\title{
The Effect of Low Protein on Colonic Mucosal Barrier in Pigs
}

\author{
El Efecto de Baja Proteína en la Barrera Mucosa Colónica en Cerdos
}

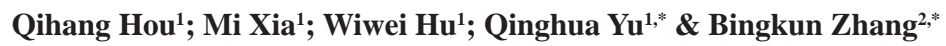

HOU, Q.; XIA, M.; HU, W.; YU, Q. \& ZHANG, B. The effect of low protein on colonic mucosal barrier in pigs. Int. J. Morphol., 35(3):877-882, 2017.

SUMMARY: Reducing nitrogen nutrients concentration in dairy food is economic for pig industry. Here, we used finishing pig as model to investigate the effect on colon mucosal barrier and nutrients absorption after reducing crude protein (CP) in dietary from 16 $\%$ to $13 \%$. The results showed that crypt depth, cells, claudin-1 and E-cadherin expression level will not be changed, which implied the integrity of colon mucosal structure. Furthermore, the expressions of ASCT1, EAAT3 and SGLT1 in colon were also maintained at normal levels in $13 \%$ CP dietary. Interestingly, the CAT1 and GLUT2 expression were increased significantly after reducing CP level to $13 \%$, which might be attributed to the compensatory nutrients absorption. This study implied that $13 \% \mathrm{CP}$ was sufficient to maintain normal colon structure and will not change intestinal morphology, which provided a basis for an ideal economic protein feed formula.

KEY WORDS: Amino acid transporter; Pig; Colon; Goblet cell; Tight junction.

\section{INTRODUCTION}

The intestines are a key part of the body's digestive tract and are responsible for absorbing nutrients from the foods. The small intestine is generally considered the digestive organ that absorbs the most nutrients. The large intestine has two main functions: storage of undigested food matter and nutrients absorption, including water, salts and vitamins that allow the body to function normally. Recent study demonstrated that the large intestine contains large number of intestinal microbiota and large intestine also absorbs nutrients that are created by the bacteria that reside there. Bacteria break down the fiber into substances called short-chain fatty acids, which are then used by the large intestine as an energy source. In the large intestine, microbiota proteases intensively degrade undigested proteins in peptide and amino acids. The amino acids are further converted to numerous bacterial metabolites, which could be absorbed through the colonic mucosa or used by intestinal microbiota (Blachier et al., 2007). Moreover, cationic and neutral AA transporter SLC7A9 mRNA abundance was similarly expressed in the large compared with small intestine, which indicate that the large intestine might contribute to amino acids absorption (Woodward et al., 2010).
The nutrients absorption in large intestine affects large intestine function, such as intestinal inflammation or an infection, which represents a group of intestinal disorders that causes prolonged inflammation of the digestive tract. Previous studies have shown that dietary nutrients could regulate the health of the gut. For example, diet-induced changes in the composition of the gut microbiome could modulate the induction of regulatory versus effector immune responses at the gut mucosa and improve health outcomes (Viladomiu et al., 2013). Moreover, high in fat and protein but low in fruits and vegetables may be associated with the increase of inflammatory bowel disease (IBD) (Hou et al., 2011). Therefore, appropriately reducing supply of dietary nitrogen could effectively alleviate intestinal inflammation without worsen the body's growth performance. And reducing dietary nitrogen levels could not only lessen the cost and burden of obtaining a good quality protein source in China, but also decrease the excretion of nitrogen into the environment all over the world. However, the precise influences of reducing nitrogen nutrients to colon health remain unknown.

\footnotetext{
${ }^{1}$ Veterinary College, Nanjing Agricultural University, Weigang 1, Nanjing, Jiangsu, 210095, PR China.

${ }^{2}$ State Key Laboratory of Animal Nutrition, College of Animal Science and Technology, China Agricultural University, Beijing, China.

This work was supported by the National Basic Research Program of China (973 program 2013CB127302), National Natural Science Foundation of China (31502024), the State Key Laboratory of Animal Nutrition Fund of China (2004DA125184F1410) and A Project Funded by the Priority Academic Program Development of Jiangsu Higher Education Institutions.
} 
In our previous study, we found that a low-protein diet supplemented with deficient amino acids could reduce the excretion of nitrogen into the environment without affecting growth performance, such us final body weight, average daily feed intake and the ratio of feed and gain (He et al., 2016). Nutrients are digested and absorbed through the gastrointestinal tract and then influence the intestinal morphological characteristics (Jezierny et al., 2010). However, the intestinal structure might also contribute to the absorption efficiency of nutrients, such as amino acids through the amino acids transporters at the intestinal epithelium (Golovchenko et al., 2012; de Julian-Ortiz et al., 2014). Previous study has demonstrated that amino acid transporters could be detected in the colon (Ugawa et al., 2001). In this experiment, we used finishing pigs as a model, and the CP level from $16 \%$ (NRC standard) to $13 \%$ in order to test the effect of different $\mathrm{CP}$ levels on the colonic mucosal barrier.

\section{MATERIAL AND METHOD}

Animals and sample collection. Twelve cross-bred (Duroc $¥$ Landrace ¥ Yorkshire) finishing pigs (average initial BW $=62.3 \mathrm{~kg}$ ) were randomly allocated to two different dietary $\mathrm{CP}$ levels: low (13\%) or normal (16\%) level of CP (group LP and group NP, respectively). There was a 3-day acclimatization period prior to the commencement of each experiment. In the experiments, diets with LP were supplemented with crystalline amino acids to achieve equal content of standardized ileal digestible Lys, Met, Thr, and Trp (NRC 2012). The composition of experimental diets used in this study is shown in Table I (He et al.). Pigs were housed individually in metabolism cages and there were 6 pigs per treatment group. Pigs had free access to feed and drinking water throughout the experimental period. This experiment lasted for 50 days. At the end of each experiment, pigs were anesthetized with an intravenous injection of sodium pentobarbital $(50 \mathrm{mg} / \mathrm{kg} \mathrm{BW})$ and then euthanized. Intestine samples were collected and immediately frozen in liquid nitrogen. Body weight of each pig was recorded at the beginning and end of the study to compute weight gains. Feed intake was calculated on a daily basis as the difference between the feed offered and the feed remained in the feeder. All procedures involving pig treatments were approved by the Animal Ethics Committees of the Institute of Subtropical Agriculture, Chinese Academy of Science of Occupational Health and Technical Safety.

Histochemistry of goblets cells. To detect the neutral and acidic glycoconjugates in the goblet cells as well as for general observation of the colonic morphology, slide sections were processed using Periodic acid-Schiff reagent (PAS) and counterstained with hematoxylin (Liu et al., 2014). Colonic crypt depth determined on hemalun-stained sections. The number of the positively stained goblet cells was determined for 10 full-length crypts using Image-ProPlus software, version 6.0 (Media Cybernetics). The values were averaged per crypt for each tissue sample (Da Silva et al., 2014).

Western blot analysis. The frozen intestinal samples were powdered using liquid nitrogen and lysed with RIPA lysis buffer. The supernatant fluid protein concentration was determined using the Tecan Infinite 200 Pro (Tecan, Switzerland). The samples were adjusted to an equal protein concentration and then diluted with $4 \times$ loading buffer to a final volume of $2.5 \mathrm{ml}$ and heated in boiling water for 5 $\mathrm{min}$. After cooling on ice, the solution was used for Western blot analysis (Kurien \& Scofield, 2015).

Table I. The composition and analyzed nutrient content of the experimental diets.

\begin{tabular}{lcc}
\hline \multirow{2}{*}{ Ingredients (\%) } & \multicolumn{2}{c}{ Dietary treatment } \\
& Group LP & Group NP \\
\hline Corn & 78.36 & 67.00 \\
Soybean meal & 15.00 & 23.76 \\
Wheat bran & 3.00 & 6.00 \\
Soybean oil & 0.90 & 0.88 \\
Lys & 0.27 & 0.01 \\
Thr & 0.06 & 0.00 \\
Trp & 0.01 & 0.00 \\
CaHPO3 & 0.55 & 0.50 \\
Rock-powder & 0.55 & 0.55 \\
Salt & 0.30 & 0.30 \\
1\% Premix & 1.00 & 1.00 \\
Nutrient composition & & \\
CP & 13.17 & 16.30 \\
Lys & 0.72 & 0.72 \\
Met +Cys & 0.42 & 0.50 \\
Thr & 0.50 & 0.56 \\
Trp & 0.13 & 0.17 \\
His & 0.31 & 0.39 \\
Ile & 0.45 & 0.60 \\
Leu & 1.13 & 1.32 \\
Phe & 0.57 & 0.71 \\
Val & 0.50 & 0.61 \\
Total Ca & 0.50 & 0.52 \\
Total P & 0.40 & 0.45 \\
Starch & 49.97 & 43.71 \\
ME,_MJ/kg_ & 14.20 & 14.20 \\
\hline Prom prove & & \\
\hline
\end{tabular}

$\dagger$ Premix provided per kg of complete diet: 10,800 IU vitamin A; 4,000 IU vitamin D3; 40 IU vitamin E; $4 \mathrm{mg}$ vitamin $\mathrm{K} 3 ; 6 \mathrm{mg}$ vitamin $\mathrm{B} 1 ; 12 \mathrm{mg}$ vitamin $\mathrm{B} 2 ; 6 \mathrm{mg}$ vitamin $\mathrm{B} 6 ; 0.05 \mathrm{mg}$ vitamin B12; $50 \mathrm{mg}$ niacin; $0.2 \mathrm{mg}$ biotin; $2 \mathrm{mg}$ folic acid; $25 \mathrm{mg}$ D-calcium pantothenate; $100 \mathrm{mg} \mathrm{Fe}$ as ferrous sulfate; $150 \mathrm{mg} \mathrm{Cu}$ as copper sulfate; $40 \mathrm{mg} \mathrm{Mn}$ as manganese oxide; $100 \mathrm{mg} \mathrm{Zn}$ as zinc oxide; $0.5 \mathrm{mg} \mathrm{I}$ as potassium iodide; and $0.3 \mathrm{mg}$ Se as sodium selenite. 
Equal quantities of the sample aliquots were subjected to $10 \%$ SDS-PAGE (10\% gradient gel) and then transferred to a PVDF membrane (Millipore, MA, USA) at $90 \mathrm{~V}$ for $100 \mathrm{~min}$ using the Bio-Rad Transblot apparatus (CA, USA). The membranes were blocked with $5 \%$ fat-free milk in TBST for 2 $\mathrm{h}$ and then incubated with an anti-CAT1 (1:1000) abcam, USA, an anti-E-cadherin (1:500) (abcam, USA), an anti-EAAT3 (1:1000), an anti-ASCT1 (1:1000), an anti-Claudin-1 (1:800), an anti-SGLT1 (1:1000), an anti-GLUT2 (1:1000) (Santa Cruz, CA, USA) or an anti-b-actin antibody (1:6000) (Vazyme Biotech, China) at 4 overnight with gentle rocking. After washing five times with TBST, the membranes were incubated at room temperature for $2 \mathrm{~h}$ with horseradish peroxidase-linked secondary antibodies (Vazyme Biotech, China). Finally, the membranes were washed with TBST followed by development using the Supersignal West Dura Extended Duration Substrate in accordance with the manufacturer's instructions (Pierce, USA). The images were detected using chemiluminescence (Applygen, China). The Western blots were quantified by measuring band intensity using the AlphaImager 2200 software. Ratios of the intensities for specific protein bands and housekeeping protein bands were calculated.

Statistical analysis. The data are presented as mean \pm standard error of the mean (SEM). The data were tested between the LP and NP levels for significance with an independent t-test method, using the statistical software SPSS 16.0. The differences were considered significant at $* \mathrm{P}<0.05, * * \mathrm{P}<0.01$.

\section{RESULTS}

The effect of dietary CP levels on crypt depth and the number of goblet cells. In the $\mathrm{A}$ previous study, we found that dietary different $\mathrm{CP}$ levels treatment had no effect on the growth performance in finishing pig, such as final body weight, average daily feed intake and the ration of feed and gain (He et al.). The growth performance results are consistent with the intestinal morphology. The $\mathrm{CP}$ concentration in the dietary did not affect the colon morphology (Fig. $1 \mathrm{~A}$ and B) and colonic crypt depth (Fig. 1 C, P > 0.05) in the finishing pigs.

Goblet cells are localized throughout the length of large intestines, which will maintain the protective mucus blanket by synthesizing and secreting highmolecular-weight glycoproteins (Johansson \& Hansson, 2013). Similarly, the number of goblet cells per crypt in colon was also not affected by the $\mathrm{CP}$ concentration in the dietary (Fig. $1 \mathrm{D}, \mathrm{P}>0.05$ ).
A

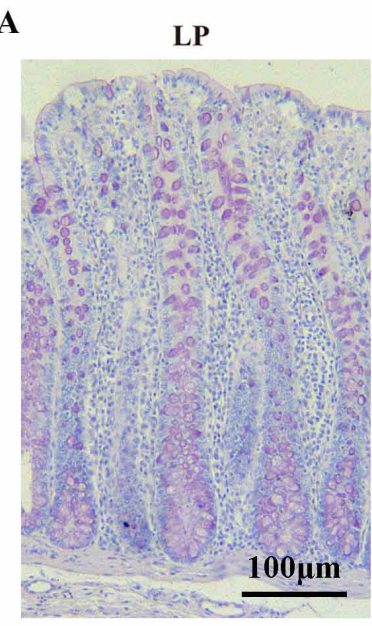

B NP

C
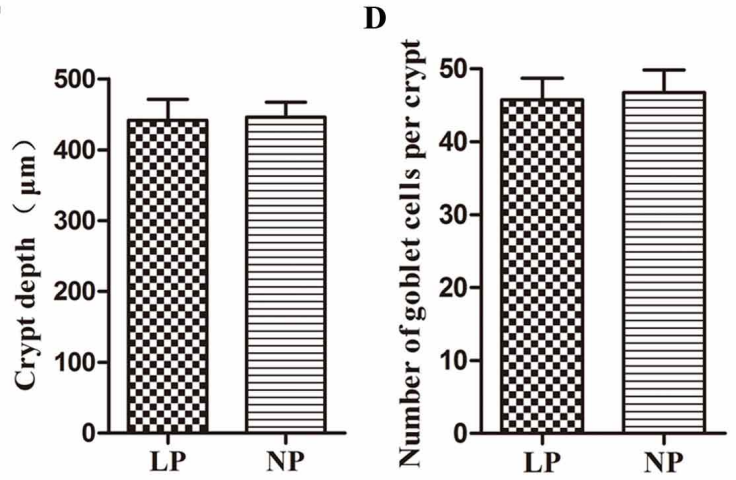

Fig. 1. The goblet cells in the colon were stained with Periodic acid-Schiff reagent (PAS) and counterstained with hematoxylin (A, B), colonic crypt depth determined on hemalun-stained sections (C) and the number of goblet cells (D) in each crypt were counted.

Scale bar $100 \mathrm{~mm}$. Values are means \pm SEM; $\mathrm{n}=6$ pigs/group.
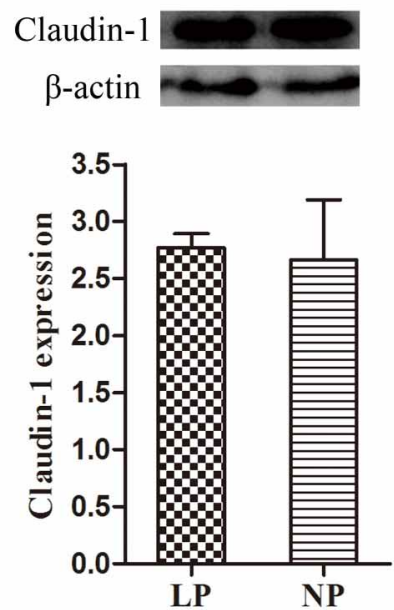

B


Fig. 2. The effect of protein levels on the cell junctions in the colon. The finishing pigs were fed with $13 \%$ and $16 \% \mathrm{CP}$ in dietary. The Claudin- 1 expression in the colon (A) and E-cadherin expression in the colon (B) were detected using Western blotting. The values are the means \pm SEM; $n=6$ pigs/group; $* \mathrm{P}<0.05$. 
The effect of dietary $\mathrm{CP}$ levels on cell junctions in the colon. Claudin-1 and E-cadherin are important component proteins of tight junctions and adhesion junctions, respectively, which control the intestinal epithelium paracellular pathway (Tang \& Goodenough, 2003; Lee $e t$ al., 2013). The tight junction is important in regulating intestinal inflammation. We did not detect a significant difference in Claudin-1 and E-cadherin expression between the NP and LP groups in colon (Fig. 2, P > 0.05).
Expression of amino acid transporters in the colon. The lumenal plasma membrane of the absorptive cell contains at least three amino acid transporters (AAT), one each for acidic, basic and neutral amino acids (Xiong et al., 2012). The results showed that compared to the NP group, the LP group (13\%) significantly stimulated expression of the basic AAT CAT1 in the colon (Fig. $3 \mathrm{~A}, * \mathrm{P}<0.05$ ). However, the dietary $\mathrm{CP}$ levels did not influence expression of the neutral AAT ASCT1 and acidic AAT EAAT3 in the colon (Fig. 3 B C, P > 0.05).
A
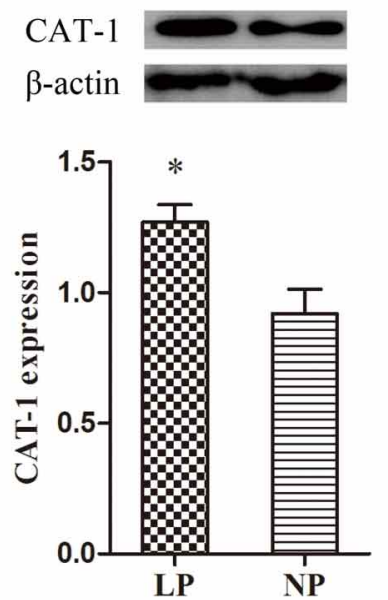

B


C
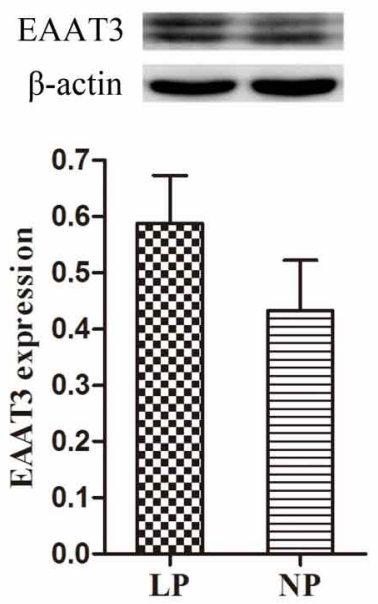

Fig. 3. The amino acid transporter expression in the colon. The finishing pigs were fed with $13 \%$ and $16 \% \mathrm{CP}$ in their diets. CAT1 expression in the colon (A); ASCT1 expression in the colon (B); and EAAT3 expression in the colon $(\mathrm{C})$ were detected through Western blotting. The values are the means $\pm \mathrm{SEM} ; \mathrm{n}=6$ pigs/group; $* \mathrm{P}<0.05$.

A
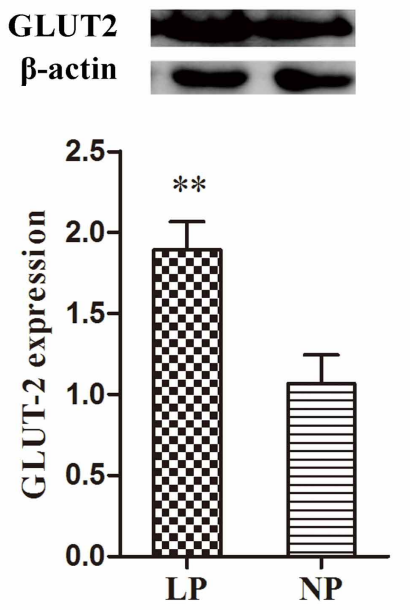

B

\section{SGLT1 $\beta$-actin}
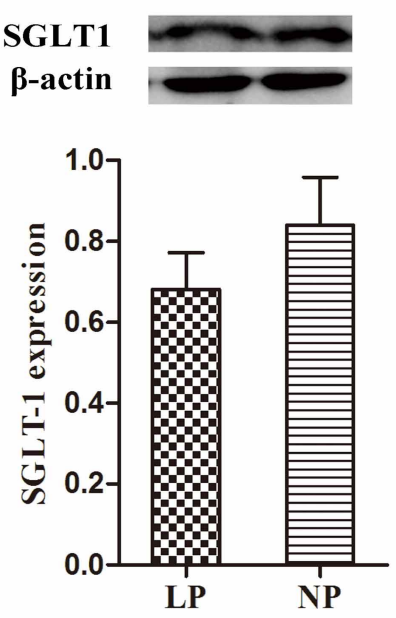

Fig. 4. The glucose transporter expression in the colon. The finishing pigs were fed with $13 \%$ and $16 \% \mathrm{CP}$ in their diets. GLUT2 expression in the colon (A) and SGLT1 expression in the colon (B) were detected through Western blotting. Values are means $\pm \mathrm{SEM} ; \mathrm{n}=6$ pigs/group; $* \mathrm{P}<0.05$. 
Expression of glucose transporters in the colon. Intestinal glucose absorption is mediated by the sodium-dependent glucose transporter SGLT1, whereas the facilitated glucose transporter GLUT2 provides a basolateral glucose exit into the blood stream (Röder et al., 2014). The results showed that compared to the NP group, the LP group (13\%) significantly stimulated expression of the GLUT2 in the colon (Fig. 4 A, $* * \mathrm{P}<0.01)$. However, the dietary $\mathrm{CP}$ levels did not influence expression of the SGLT1 in the colon (Fig. 4 B, P > 0.05).

\section{DISCUSSION}

Reducing the concentration of nitrogen nutrients in the dietary is health for human, reducing the ratio of IBD. Our previous study demonstrated that the ileal digestibilities of $\mathrm{CP}$, dry matter (DM) were increased significantly in the LP group compared to NP group, although the mRNA levels for digestive enzymes were not changed (He et al.). Moreover, the LP diet supplemented with deficient amino acids also did not affecting growth performance, including the final body weight. In this study, we found that LP in dietary did not exhibit effects on claudin- 1 and E-cadherin expression in the colon, which is essential for the protection of mucosal barrier integrity. The above results indicated that low protein concentration $(13 \%)$ in the dietary could maintain normal colonic morphology and the integrity of colonic mucosal barrier. This was also further confirmed by the similar number of goblet cells and crypt depth between LP group and NP group. Most interestingly, in previous study, we found that the final body weight, feed to gain ratio and average daily feed intake did not differ significantly between the LP and NP groups (He et al.). This may be explained by the enhancement of absorption efficiency under reducing the dietary CP concentration to $13 \%$.

Dietary protein is hydrolyzed by digestive proteases to absorbable constituents, including dipeptides, tripeptides, and amino acids. Amino acids are efficiently absorbed by the intestinal epithelium through AAT (Mourad et al., 2009). Reducing protein concentration in dietary will not affect the ASCT1 and EAAT3 expression, which implied low protein could also guarantee amino acid absorption. CAT1 is responsible for transporting lysine, arginine and ornithine (Hosoya et al., 2010). The LP group exhibited an increase in CAT1 expression in the colon compared with the NP group, which may be a compensatory mechanism of enhancing nutrients absorption in low protein environment.

Colon may also be involved in amino acid and glucose absorption (Ugawa et al.; Blachier, 2013). SGLT1 and GLUT2 are the main intestinal glucose transporters and play an important role in intestinal glucose sensing (Röder et al.). SGLT1 is unequivocally the prime intestinal glucose transporter even at high luminal glucose concentrations. Recently, scholars postulated that GLUT2 could be recruited into the apical membrane after a high luminal glucose load, which allows for bulk absorption of glucose by facilitated diffusion (Röder $e t a l$.). The results show the SGLT1 expression in the colon in the LP group will not be affected, and the GLUT2 expression will be increased, which will guarantee for stable glucose absorption and metabolize.

In conclusion, we presume that the large intestine does not play an important role in nutrient absorption because it only absorbs water, inorganic salt and certain vitamins (Higaki et al., 2001). In this study, AATs and glucose transporters was also detected in the colon. Furthermore, the LP group exhibited a significant increase in CAT1 and GLUT2 expressions in the colon compared with the NP group to maintain nutrients absorption in low protein dietary. This study demonstrated that low protein dietary is sufficient to protect the colon integrity and nutrition absorption, which will support the application of low protein dietary in preventing intestinal inflammation in colon.

\section{ACKNOWLEDGEMENTS}

The authors appreciate Tiejun $\mathrm{Li}$ and $\mathrm{Li} \mathrm{Wu}$, from the Institute of Subtropical Agriculture, The Chinese Academy of Science, for animal feeding and kind help during sampling.

HOU, Q.; XIA, M. \& YU, Q. El efecto de baja proteína en la barrera mucosa colónica en cerdos. Int. J. Morphol., 35(3):877882, 2017.

RESUMEN: La reducción de concentración de nitrógeno en los alimentos lácteos es económicamente favorable para la industria porcina. En este trabajo se utilizó el cerdo de acabado como modelo para investigar el efecto sobre la barrera de la mucosa del colon y la absorción de nutrientes después de reducir la proteína bruta (CP) en la dieta del $16 \%$ al $13 \%$. Los resultados mostraron que la profundidad de la cripta, las células globulares, el nivel de expresión de Claudin-1 y E-cadherina no cambiaron, lo que implicaría la integridad de la estructura de la mucosa del colon. Además, las expresiones de ASCT1, EAAT3 y SGLT1 en el colon también se mantuvieron en niveles normales en el $13 \%$ de la dieta de CP. Sin embargo, la expresión de CAT1 y GLUT2 incrementó 
significativamente después de reducir el nivel de CP a $13 \%$, lo que podría atribuirse a la absorción de nutrientes compensatorios. Este estudio indicó que el CP del $13 \%$ era suficiente para mantener la estructura normal del colon y no cambiaría la morfología intestinal, lo que proporcionó una base para una fórmula económica ideal para la alimentación con proteínas.

PALABRAS CLAVE: Transportador de aminoácidos; Cerdo; Colon; Células caliciformes; Unión estrecha

\section{REFERENCES}

Blachier, F.; Mariotti, F.; Huneau, J. F. \& Tomé, D. Effects of amino acidderived luminal metabolites on the colonic epithelium and physiopathological consequences. Amino Acids, 33(4):547-62, 2007.

Blachier, F. Fate of proteins and amino acids in the small and large intestine: what consequences for the mucosa? In: Abstracts presented at the 13th International Congress on Amino acids, peptides and proteins. Amino Acids, 45(3):577-8, 2013.

Da Silva, S.; Robbe-Masselot, C.; Ait-Belgnaoui, A.; Mancuso, A.; MercadeLoubière, M.; Salvador-Cartier, C.; Gillet, M.; Ferrier, L.; Loubière, P.; Dague, E.; Theodorou, V. \& Mercier-Bonin, M. Stress disrupts intestinal mucus barrier in rats via mucin O-glycosylation shift: prevention by a probiotic treatment. Am. J. Physiol. Gastrointest. Liver Physiol., 307(4):G420-9, 2014.

de Julian-Ortiz, J. V.; Zanni, R.; Galvez-Llompart, M. \& Garcia-Domenech, $\mathrm{R}$. The prediction of human intestinal absorption based on the molecular structure. Curr. Drug Metab., 15(4):380-8, 2014.

Golovchenko, V. V.; Khramova, D. S.; Ovodova, R. G.; Shashkov, A. S. \& Ovodov, Y. S. Structure of pectic polysaccharides isolated from onion Allium cepa L. using a simulated gastric medium and their effect on intestinal absorption. Food Chem., 134(4):1813-22, 2012.

He, L.; Wu, L.; Xu, Z.; Li, T.; Yao, K.; Cui, Z.; Yin, Y. \& Wu, G. Lowprotein diets affect ileal amino acid digestibility and gene expression of digestive enzymes in growing and finishing pigs. Amino Acids, 48(1):2130, 2016.

Higaki, K.; Yata, T.; Sone, M.; Ogawara, K. \& Kimura, T. Estimation of absorption enhancement by medium-chain fatty acids in rat large intestine. Res. Commun. Mol. Pathol. Pharmacol., 109(3-4):231-40, 2001.

Hosoya, K.; Ichikawa, T.; Akanuma, S.; Hirose, S. \& Tachikawa, M. Glycine and L-arginine transport in cultured Müller glial cells (TR-MUL). Neurochem. Int., 57(3):262-8, 2010.

Hou, J. K.; Abraham, B. \& El-Serag, H. Dietary intake and risk of developing inflammatory bowel disease: a systematic review of the literature. Am. J. Gastroenterol., 106(4):563-73, 2011.

Jezierny, D.; Mosenthin, R. \& Bauer, E. The use of grain legumes as a protein source in pig nutrition: A review. Anim. Feed Sci. Technol., 157(3-4):111$28,2010$.

Johansson, M. E. \& Hansson, G. C. Mucus and the goblet cell. Dig. Dis., 31(3-4):305-9, 2013.

Kurien, B. T. \& Scofield, R. H. Western blotting: an introduction. Methods Mol. Biol., 1312:17-30, 2015.

Lee, S. Y.; Han, S. M.; Kim, J. E.; Chung, K. Y. \& Han, K. H. Expression of E-cadherin in pig kidney. J. Vet. Sci., 14(4):381-6, 2013.

Liu, P.; Pieper, R.; Rieger, J.; Vahjen, W.; Davin, R.; Plendl, J.; Meyer, W. \& Zentek, J. Effect of dietary zinc oxide on morphological characteristics, mucin composition and gene expression in the colon of weaned piglets. PLoS One, 9(3):e91091, 2014.

Mourad, F. H.; Barada, K. A.; Khoury, C.; Hamdi, T.; Saadé, N. E. \& Nassar, C. F. Amino acids in the rat intestinal lumen regulate their own absorption from a distant intestinal site. Am. J. Physiol. Gastrointest. Liver Physiol., 297(2):G292-8, 2009.

882
Röder, P. V.; Geillinger, K. E.; Zietek, T. S.; Thorens, B.; Koepsell, H. \& Daniel, H. The role of SGLT1 and GLUT2 in intestinal glucose transport and sensing. PLoS One, 9(2):e89977, 2014.

Tang, V. W. \& Goodenough, D. A. Paracellular ion channel at the tight junction. Biophys. J., 84(3):1660-73, 2003.

Ugawa, S.; Sunouchi, Y.; Ueda, T.; Takahashi, E.; Saishin, Y. \& Shimada, S. Characterization of a mouse colonic system $\mathrm{B}(0+)$ amino acid transporter related to amino acid absorption in colon. Am. J. Physiol. Gastrointest. Liver Physiol., 281(2):G365-70, 2001.

Viladomiu, M.; Hontecillas, R.; Yuan, L.; Lu, P. \& Bassaganya-Riera, J. Nutritional protective mechanisms against gut inflammation. J. Nutr. Biochem., 24(6):929-39, 2013.

Woodward, A. D.; Holcombe, S. J.; Steibel, J. P.; Staniar, W. B.; Colvin, C. $\&$ Trottier, N. L. Cationic and neutral amino acid transporter transcript abundances are differentially expressed in the equine intestinal tract. $J$. Anim. Sci., 88(3):1028-33, 2010.

Xiong, X.; Yang, C. B. \& Yin, Y. L. Research progress on intestinal amino acid and amino acid transporters. Sheng Li Ke Xue Jin Zhan, 43(3):2026, 2012.

\author{
Corresponding author: \\ Qinghua Yu \\ Veterinary College \\ Nanjing Agricultural University \\ Weigang 1, Nanjing, Jiangsu, 210095 \\ PR CHINA
}

E-mail: yuqinghua1981@163.com

\author{
Corresponding author: \\ Bingkun Zhang \\ State Key Laboratory of Animal Nutrition \\ College of Animal Science and Technology \\ China Agricultural University \\ Beijing \\ CHINA
}

E-mail: bingkunzhang@126.com

Received: 20-03-2017

Accepted: 05-06-2017 